\title{
Influence of Elevated Temperatures on the High-Strength X3NiCoMoTi 18-9-5 Maraging Steel Behavior
}

\author{
Angelina Strakosova, Alena Michalcová, Zdeněk Kačenka, Filip Průša, Dalibor Vojtěch \\ Department of Metals and Corrosion Engineering, University of Chemistry and Technology Prague. Technická 5, \\ 16628 Prague. Czech Republic. E-mail: Angelina1.Strakosova@vscht.cz, Alena.Michalcova@vscht.cz, \\ Zdenek.Kacenka@vscht.cz,Filip.Prusa@vscht.cz,Dalibor.Vojtech@vscht.cz
}

High-strength X3NiCoMoTi 18-9-5 maraging steel belongs to highly researched materials due to its wide application range. Thanks to its outstanding mechanical properties, it is usually used for high-loaded parts in the aircraft and aerospace industry. Hardness and ultimate tensile strength are strongly affected by heat treatment allowing to create $\mathrm{Ni}_{3} \mathrm{X}(\mathrm{X}=\mathrm{Mo}, \mathrm{Ti}), \mathrm{Fe}_{2} \mathrm{Mo}$, and $(\mathrm{Fe}, \mathrm{Ni}, \mathrm{Co})_{3}(\mathrm{Ti}, \mathrm{Mo})$ precipitate which almost doubles their properties. In the present study, microstructure and mechanical properties of the thermo-mechanically processed maraging steel were studied two modes of heat treatment. Microhardness values improved from $350 \mathrm{HV} 0.1$ to $650 \mathrm{HV0.1}$, and ultimate tensile strength has increased from 1029 up to $2140 \mathrm{MPa}$. On the contrary, elongation has reduced from 11 to $4 \%$. After heat treatment, precipitates $\mathrm{Ni}_{3} \mathrm{Mo}$ has been formed in the material volume.

Keywords: Maraging, Forging, Microstructure, Heat treatment, Precipitation hardening

\section{Introduction}

The X3NiCoMoTi 18-9-5 (1.2709 in European classification) is one of a few types of maraging steels, composed of $\mathrm{Ni}, \mathrm{Co}, \mathrm{Mo}, \mathrm{Ti}$ as the main alloying elements that improve the mechanical properties. Maraging steel is used mainly in tooling applications and in the aircraft industry [1-4]. Besides that, it can be used as ultra-high-speed material for rotors in electric hysteresis motors [5, 6]. The X3NiCoMoTi 18-9-5 alloy has an excellent combination of high tensile strength, hardness and toughness. One of the other advantages is good dimensional stability after heat treatment [1]. Among the already mentioned, it is also easily weldable due to low content of $\mathrm{C}$. This allows producing this type of steel by a variety of methods including conventional casting, selective laser melting (SLM) or powder metallurgy (PM) techniques [7-11].

The excellent mechanical properties of the maraging steel are achieved by common heat treatment. It consists of two steps: solution annealing at temperatures around $800{ }^{\circ} \mathrm{C}$ and of subsequent aging of the steel. During solution annealing, the grain size increases and the material becomes softer with average hardness values of $30 \mathrm{HRC}$ [5]. In the aging step typically done at a temperature range of $450-600{ }^{\circ} \mathrm{C}$, a formation of homogeneously dispersed intermetallic precipitates identified as $\mathrm{Ni}_{3} \mathrm{X}(\mathrm{X}=\mathrm{Mo}, \mathrm{Ti}), \mathrm{Fe}_{2} \mathrm{Mo}$, and $(\mathrm{Fe}, \mathrm{Ni}$, $\mathrm{Co})_{3}(\mathrm{Ti}, \mathrm{Mo})$ occurs $[5,7,12]$. The precipitates are distributed throughout the material volume strongly strengthening a soft martensite matrix.

In our previous work [11], the influence of heat treatment on microstructure and mechanical properties of the 3D-printed high-strength X3NiCoMoTi 18-9-5 maraging steel has been investigated. It was found, that the aging done at $490{ }^{\circ} \mathrm{C}$ provides the highest increase in mechanical properties of such prepared material. Since the techniques of maraging steels preparation vary, the temperature range for the aging might be slightly different for those prepared by much more conventional methods shifting the temperatures up to higher values to achieve the maxima of properties.

Thus, this work is focused on microstructure and mechanical properties change of the forged highstrength X3NiCoMoTi 18-9-5 maraging steel that undergone two different heat treatment modes composed of solution annealing and subsequent aging treatment and of simply aging. The change of the microstructure was observed and fully described in respect to the forging axis and perpendicular direction.

\section{Experiment}

Commercially produced X3NiCoMoTi 18-9-5 maraging steel (also denoted as CRYODUR 2709 ULTRACLEAN) bar has been purchased from SCHMOLZ + BICKENBACH s.r.o company. The steel bar was remelted, forged, solution annealed, quenched, and straightened to release internal stresses induced during heat treatment. Further details of the production are unknown since they are considered as a company secret. The chemical composition of the steel was determined by XRF analysis (ARL 9400) which results are shown in Table 1. 
Tab. 1 Chemical composition of the forged X3NiCoMoTi 18-9-5 maraging steel (in wt. \%)

\begin{tabular}{|c|c|c|c|c|c|c|c|c|c|c|c|c|}
\hline Element & $\mathbf{F e}$ & $\mathbf{C}$ & $\mathbf{N i}$ & $\mathbf{C o}$ & $\mathbf{M o}$ & $\mathbf{T i}$ & $\mathbf{A l}$ & $\mathbf{M n}$ & $\mathbf{S i}$ & $\mathbf{C u}, \mathbf{C r}$ & $\mathbf{Z r}$ & $\mathbf{P}$ \\
\hline wt.\% & Bal. & $\leq 0.03$ & 19.4 & 9.03 & 4.79 & 1.02 & 0.1 & 0.09 & 0.05 & $\leq 0.16$ & 0.01 & 1.75 \\
\hline
\end{tabular}

Heat treatment parameters consisted of solution annealing at $820^{\circ} \mathrm{C} / 1 \mathrm{~h}$ and aging at $490^{\circ} \mathrm{C} / 6 \mathrm{~h}$, both accompanied by slow air cooling. We tested two approaches, first consisting of solution annealing and aging while the second consisted of aging, both done in electric resistance furnaces. X-ray diffraction (using Co $\mathrm{K} \propto 0.17929 \mathrm{~nm}$, PANalytical X'Pert PRO) was used to identify the present phases within the steel as a consequence of chosen heat treatment. For this purpose, the scans were done from 6 to $110^{\circ}$ with a step size of $0.033^{\circ}$ and $81.28 \mathrm{~s}$ dwell time.

The cross-section specimens were prepared by grinding on P280-P4000 SiC abrasive papers followed by polishing on a $2 \mu \mathrm{m}$ diamond paste and on an Eposil F suspension. The prepared samples were then etched in a solution containing $2 \mathrm{ml} \mathrm{HNO}_{3}+98 \mathrm{ml}$ ethanol (commonly denoted as Nital2). The microstructure of prepared samples was observed using the light microscope (LM, Olympus PME3). A detailed study of the material microstructure evolution during heat treatment was documented using a transmission electron microscope (TEM, JEOL 2200 FS) equipped by an energy-dispersive X-ray spectroscope (EDS, OXFORD Instruments, $80 \mathrm{~mm}^{2}$ ).

The universal testing machine LabTest 5.250SP1VM (LaborTech, Opava, Czech Republic) has been used to perform the tensile test of the maraging steel. Samples in a dog-bone shape have been made from the forged bar along the forging direction. Measurements were done at laboratory temperature evaluating the different heat treatment. The Vickers microhardness HV 0.1 of the prepared and thermally treated samples was measured at least on 10 different places with a $10 \mathrm{~s}$ dwell time using FUTURE TECH FM-700 testing machine.

\section{Results and Discussion}

The microstructure of the studied as-forged X3NiCoMoTi 18-9-5 maraging steel is shown in Figure 1. As can be seen, it consists of coarse martensite laths, which are a result of the technological process of maraging steel production. The formation of martensite was caused due to a high temperature of solution annealing and subsequent rapid quenching.

Figure 2 shows the microstructure changes after the chosen heat treatment setup. As one can see, there were no changes in the microstructure of the investigated alloy after the first heat treatment mode which consisted of solution annealing at $820^{\circ} \mathrm{C} / 1 \mathrm{~h}$ and subsequential aging at $490{ }^{\circ} \mathrm{C} / 6 \mathrm{~h}$ (see Fig. 2a). The microstructure was composed of martensite, although its laths have become finer. Almost identical effect on the microstructure was observed when only aging at 490 ${ }^{\circ} \mathrm{C} / 6 \mathrm{~h}$ has been used (Fig. 2b). Thus, both the chosen heat treatments affected the microstructure resulting in finer martensitic structure.

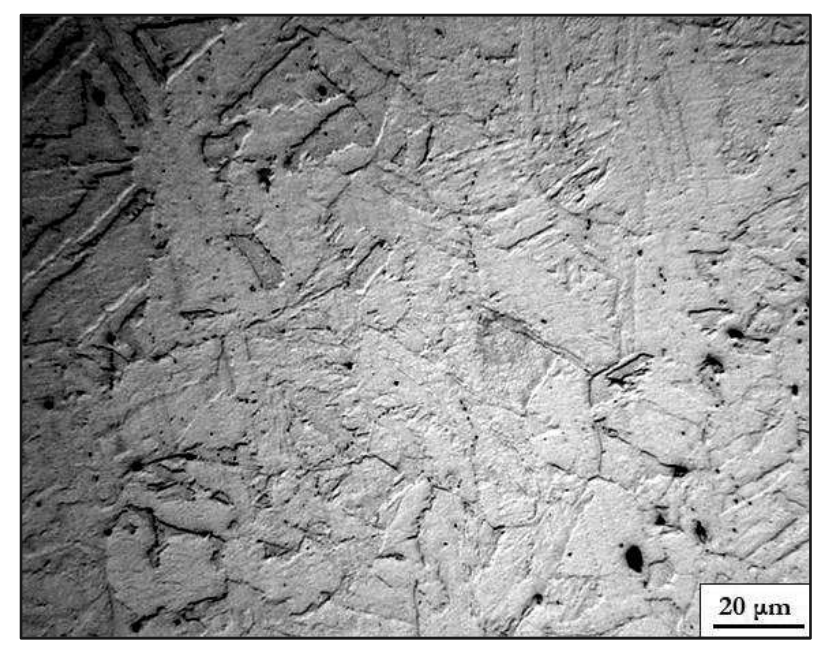

Fig. 1 LM image of the as-forged X3NiCoMoTi 18-9-5 maraging steel
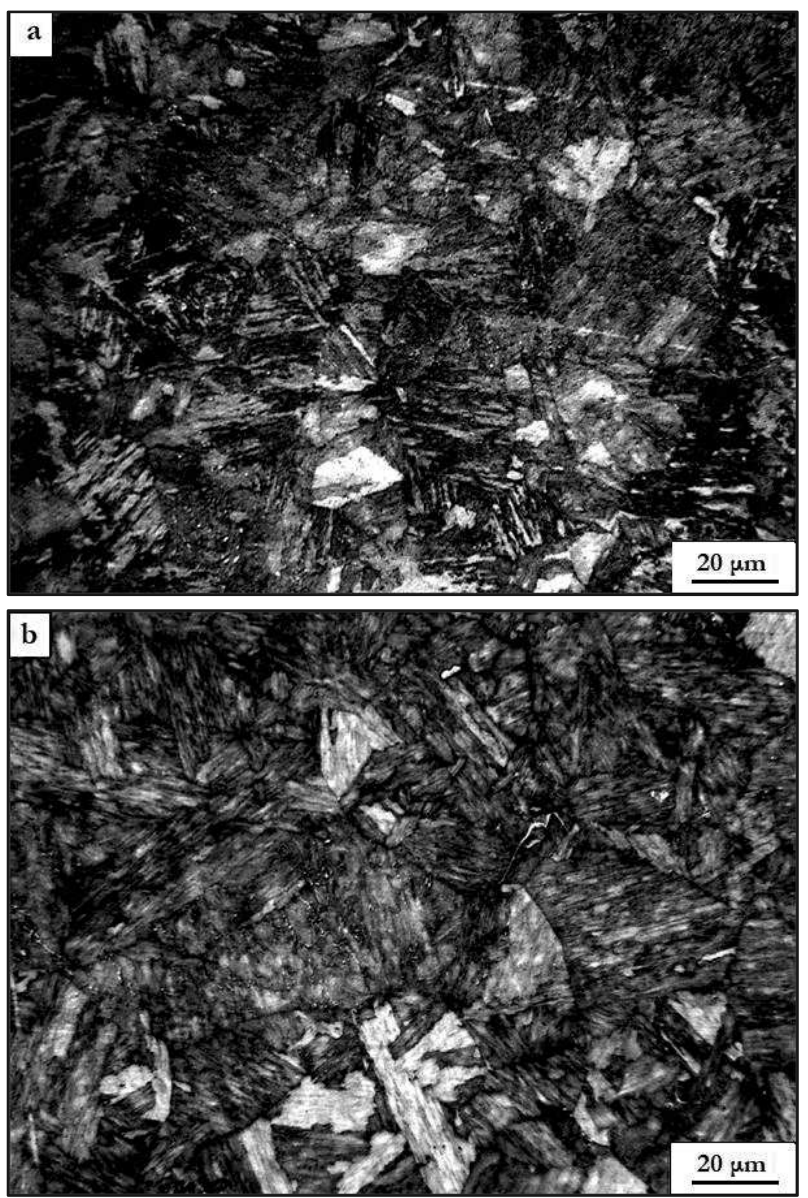

Fig. 2 LM images of the X3NiCoMoTi 18-9-5 maraging steel showing the microstructure after: a) solution annealing and aging, b) aging 
The XRD patterns of the studied material documenting the influence of chosen heat treatment are shown in Fig.3. There are only three characteristic peaks on each pattern which corresponds to $\alpha$-phase (martensite). X-ray diffraction quantification was made to prove the existence of a full-martensite structure. The results have shown that the studied steel had $100 \%$ alpha-phase in each state: as-forged, solution annealed plus aged even in the only aged one. This illustrates the main purpose of this steel that is considered as self-hardening which allows the austenite to spontaneously transform to martensite.

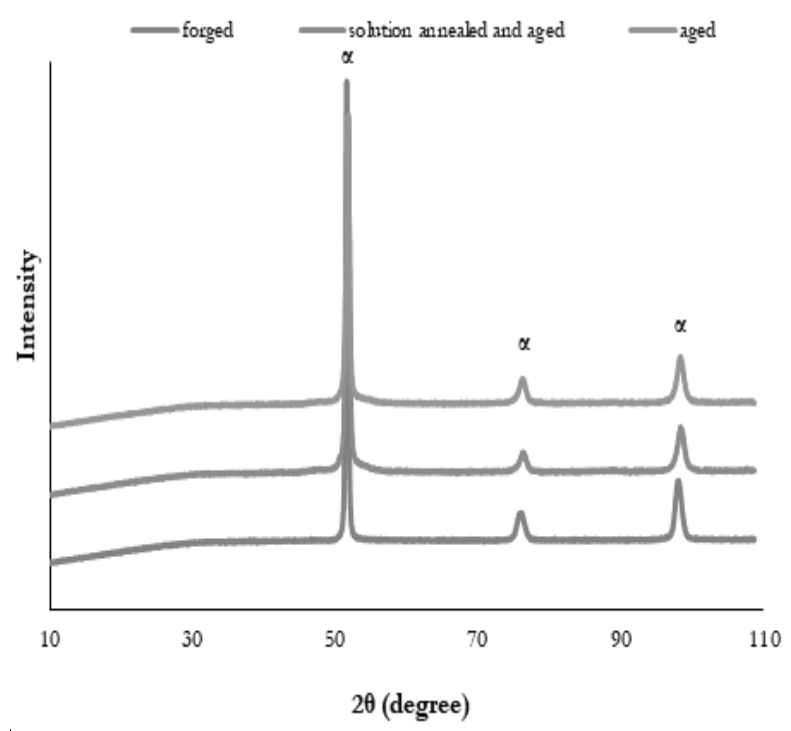

Fig. 3 XRD pattern of the X3NiCoMoTi 18-9-5 maraging steel in a different state of chosen processing

Figure 4 shows detailed TEM micrographs displaying structural components of the maraging steel as a result of different heat treatment modes.

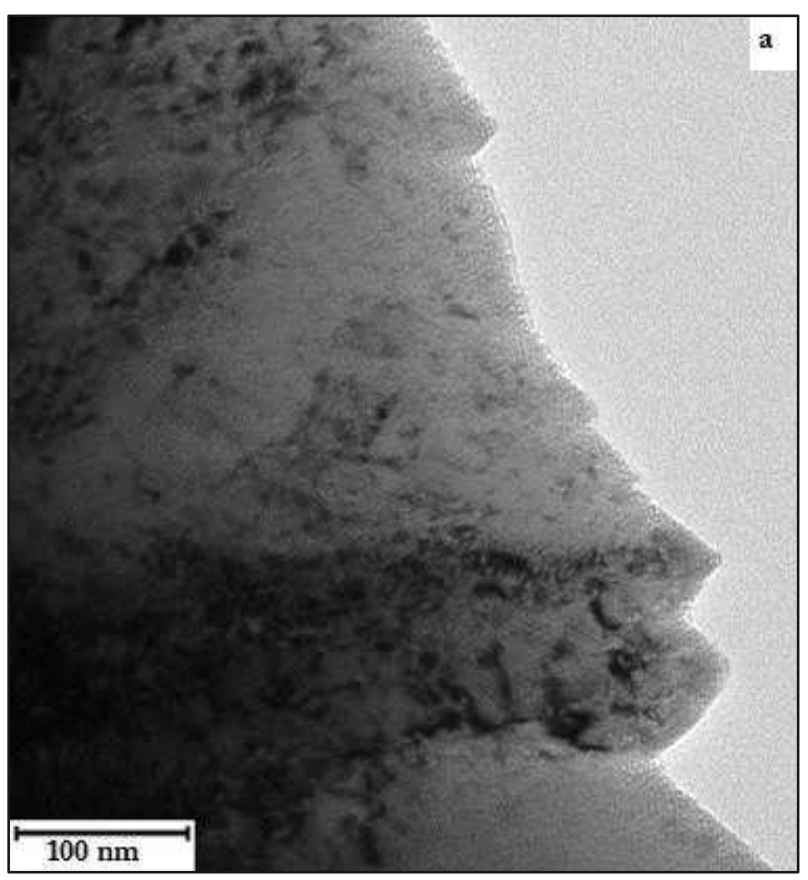

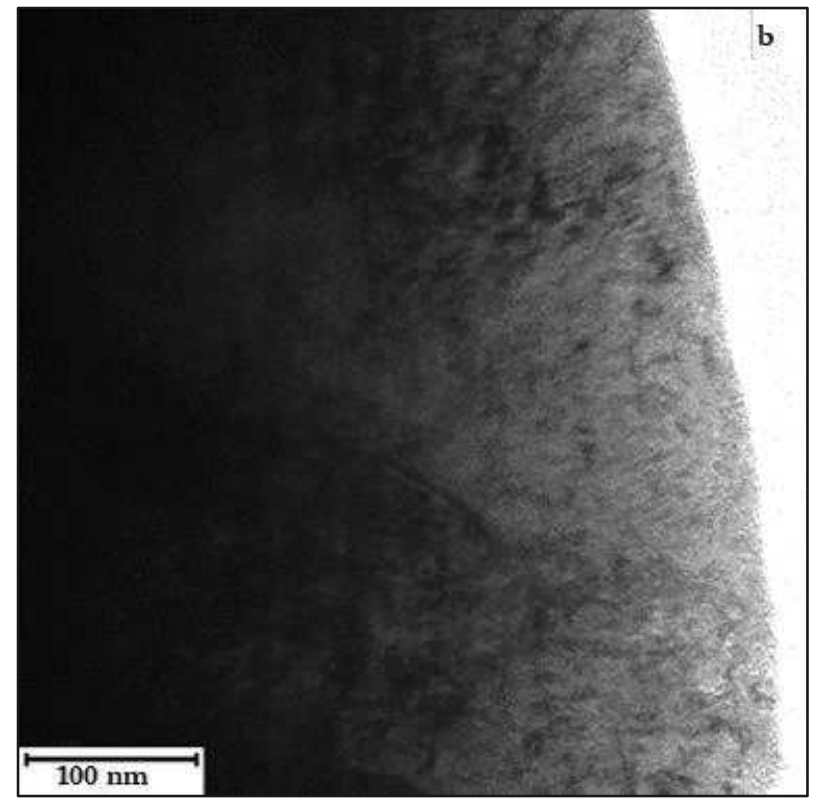

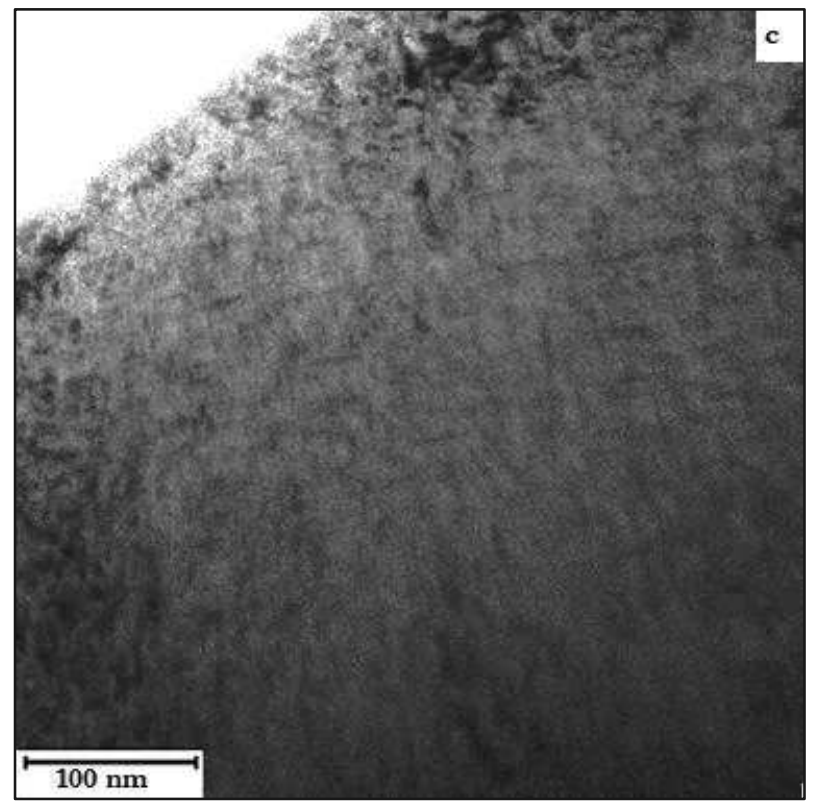

Fig. 4 TEM micrographs of the investigated maraging steel showing: a) as-forged; b) solution annealed and aged; c) aged state

One can see that the steel contained a lot of lattice defects mainly composed of dislocations in the asforged state (Fig. 4a). Defects were shown as dark fields randomly distributed in the studied area of the material. Comparing the as-forged (Fig. 4a) and both the thermally treated materials (Fig. 4b, c), one can see the obvious difference mainly caused by the higher content of lattice defects (as-forged state) and their annihilation after heat treatments which allowed to form rod-like precipitates within the martensite matrix. In addition, a lower amount of lattice defects such as highly-localized dislocation pile-ups were found in both the thermally treated materials.

The selected area electron diffraction (SAED) was used to identify the precipitates that are usually found 
in this material. The SAED patterns confirmed the absence of precipitates in the as-forged sample (see Fig. 4a). Similar SAED spectra for the thermally treated samples including that of solution annealed plus aged and just aged samples are shown in Fig. 4b, c. There are some visible differences in the atom distributions when compared to as-forged material. Accordingly to the SAED results, these reflections corresponded to the presence of $\mathrm{Ni}_{3} \mathrm{Mo}$ precipitates, both found in the thermally treated samples. According to our previous work [11], the formation of this type of precipitates was accompanied by a rapid increase in mechanical properties in the identical maraging steel produced by SLM additive manufacturing.

Mechanical properties such as microhardness and tensile tests of the investigated maraging steel were tested to determine the influence of different heat treatments. To eliminate any anisotropy of properties, the microhardness was measured in both directions which results are shown in Fig. 6.
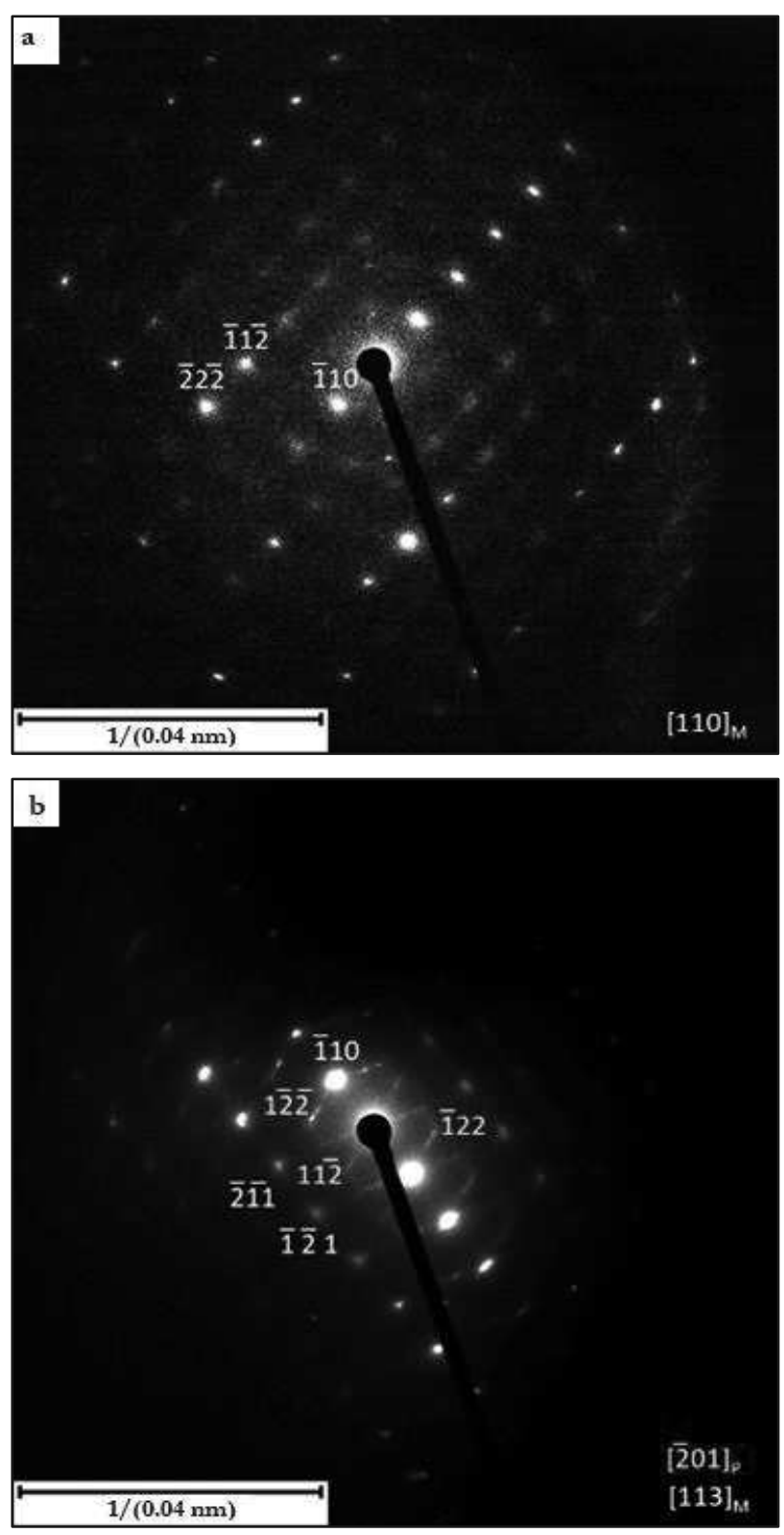

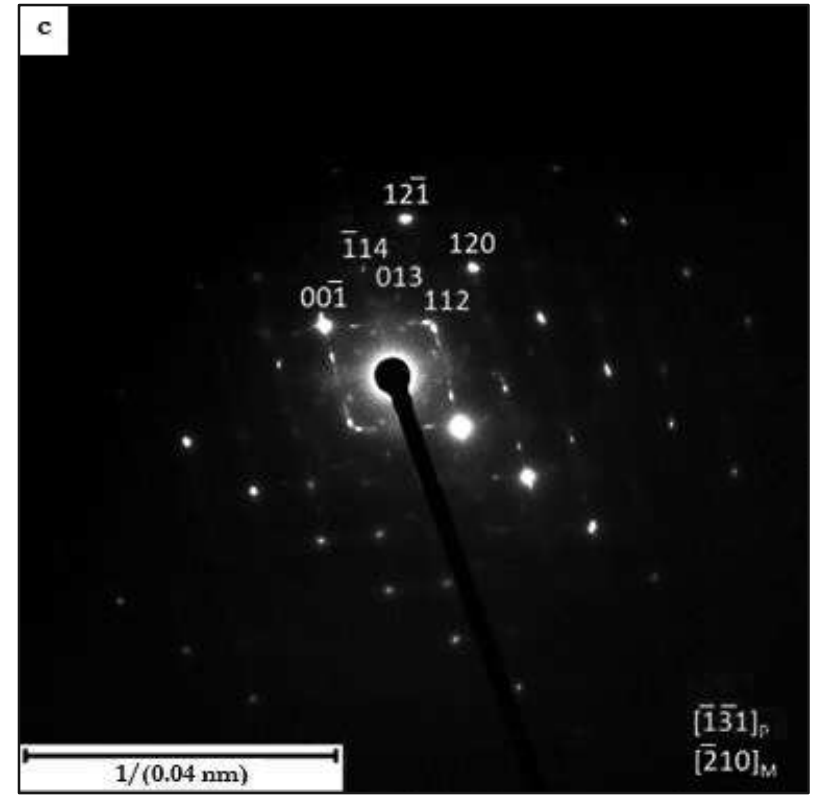

Fig. 5 SAED patterns of the maraging steel showing: a) asforged; b) solution annealed plus aged; c) aged state

For this purpose, ten measurements were done in both directions to provide complex results of the mechanical properties and their change with chosen heat treatment. It is clearly demonstrated, that the applied heat treatment improved the microhardness of the steel almost two times. In the as-forged state, the microhardness values were about $328.7 \pm 12.4$ and 338.2 \pm 9.3 HV0.1, corresponding to the forging direction and perpendicular, respectively. Microhardness of heat-treated samples has increased up to 635 HV0.1 increasing the initial by almost two times. Furthermore, it was also proved that the materials were showing uniform results regardless of the chosen direction for testing.

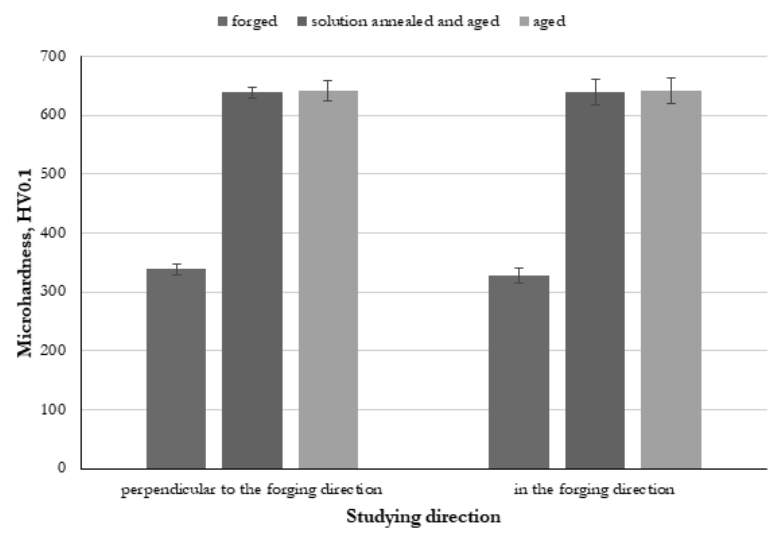

Fig. 6Microhardness HVO.1 of the forged maraging steel and its change as a result of heat treatment and orientation against the forging axis

The prepared dog-bone like specimens, extracted from the samples along the forging direction, were tensile tested and their results are shown in Tab. 2. The 
heat-treated materials significantly exceeded the properties of the as-forged material reaching tensile yield strength (TYS) up to $2050 \mathrm{MPa}$ and ultimate tensile strength (UTS) of $2141 \mathrm{MPa}$. The observed increase was almost two times higher compared to the asforged state, although the ductility lowered from 12\% down to $3.5 \%$.

Tab. 2 Results of tensile test of the investigated materials documenting the change of mechanical properties after heat treatment

\begin{tabular}{|c|c|c|c|}
\hline $\begin{array}{c}\text { State of } \\
\text { material }\end{array}$ & $\mathbf{A}$ & $\begin{array}{c}\text { UTS } \\
{[\mathbf{M P a}]}\end{array}$ & $\begin{array}{c}\text { TYS } \\
{[\mathbf{M P a}]}\end{array}$ \\
\hline As-forged & 11.7 & 1029.3 & 969.6 \\
\hline $\begin{array}{c}\text { Solution } \\
\text { annealed } \\
\text { and aged }\end{array}$ & 3.5 & 2141.3 & 2050.3 \\
\hline Aged & 4.6 & 2076 & 2015 \\
\hline
\end{tabular}

This observed improvement of mechanical properties is a direct consequence of the above-described precipitation hardening via Ni3Mo precipitates (Fig. 4b, c and Fig. 5 b, c), that occurred in both the tested heat treatments. Compared to our previous study [11], herein reported as-forged material has similar mechanical properties including hardness, UCT and YCS to the 3D-printed material prior to any heat treatment. However, the thermally treated steel had higher strength values compared to heat-treated 3D-printed maraging steel.

\section{Conclusions}

The influence of two heat treatment modes on microstructure and mechanical properties of the asforged high-strength X3NiCoMoTi 18-9-5 maraging steel was studied. The microstructure of the as-forged material consisted of coarse martensite laths, which refined becoming finer after heat treatment combining solution annealing plus aging and simply aging. The results of the tensile testing have shown that heattreated samples increased their mechanical properties almost two times. Such increase was caused by homogeneous precipitation of $\mathrm{Ni}_{3} \mathrm{Mo}$ precipitates which acted as strengthening phase within the microstructure. Furthermore, it was proved that the solution annealing does not have any significant influence on the resulting properties of the steel. Thus, from this point of view, the solution annealing is unnecessary and could be omitted.

\section{Acknowledgment}

The research was supported by the grant of Specific university research A1_FCHT_2020_003. The authors acknowledge the assistance provided by the Research Infrastructure NanoEnviCz, supported by the Ministry of Education, Youth and Sports of the Czech Republic under Project No. LM2018124.

\section{References}

[1] JAGADISH, C.A., PRIYANKA, N. (2017). Effect of Cryogenic Treatment on the Mechanical Properties of $18 \mathrm{Ni}-300$ Grade Maraging Steel Built Using the Direct Metal Laser Sintering (DMLS) Technology [C], Key Engineering Materials. Trans Tech Publications: 719, pp. 114 121.

[2] BAI, Y., YANG, Y., XIAO, Z., et al. (2018). Selective laser melting of maraging steel: mechanical properties development and its application in mold, Rapid Prototyp. J.: 24 (3), pp. 623-629.

[3] CASALINO, G., CAMPANELLI, S.L., CONTUZZI, N., et al. (2015). Experimental investigation and statistical optimisation of the selective laser melting process of a maraging steel, Optic Laser. Tecbnol:: 65, pp. 151-158.

[4] BAKSA, T., FARSKY, J., HRONEK, O., ZETEK, M. (2019). Surface quality after grinding VACO 180 tool steel using different cutting conditions. Manufacturing Technology, Vol. 19, No. 2, 2019, pp. 179-183.

[5] TAVARES, S.S.M., Da SILVA, M.R., NETO, J.M., PARDAL, J.M., CINDRA FONSECA, M.P., ABREU, H.F.G. (2004). J Alloys Compounds: 373, p. 304.

[6] PARDAL, J.M., TAVARES, S.S.M., CINDRA FONSECA, M.P., Da SILVA, M.R., et al. (2017). Influence of temperature and aging time on hardness and magnetic properties of the maraging steel grade 300. J Mater Sci: 42, pp. 2276-2281.

[7] CASATI, R., LEMKE, J.N., TUISSI, A., VEDANI, M. (2016). Aging behaviour and mechanical performance of 18 -Ni 300 steel processed by selective laser melting. Metals: 6, p. 218.

[8] TAN, C., ZHOU, K., TONG, X., et al. (2017). Microstructure and Mechanical Properties of 18Ni-300 Maraging Steel Fabricated by Selective Laser melting, 2016 6th International Conference on Advanced Design and Manufacturing Engineering (ICADME 2016), Atlantis Press.

[9] ANTSIFEROV, V.N., KOLBENEV, Yu, M. A Maraging Steel Produced by the Powder Metallurgy Method. Perm' Engineering Institute. Translated from Poroshkovaya Metallurgiya, No. 4 (112), pp. 40-43. 
[10] MENAPACE, C., LONAEDELLI, I., MOLINARI, A. (2010). Phase transformation in a nanostructured M300 maraging steel obtained by SPS of mechanically alloyed powders. $J$ Therm Anal Calorim: 101, pp. 815-821.

[11] STRAKOSOVA, A., KUBÁSEK, J., MICHALCOVÁ, A., PRŮŠA, F., VOJTĚCH, D., DVORSKÝ, D. (2019). High strength
X3NiCoMoTi 18-9-5 maraging steel prepared by selective laser melting from atomized powder. Materials: 12.

[12] LI, K., YU, B., MISRA, R.D.K., et al. (2018). Strengthening of cobalt-free $19 \mathrm{Ni} 3 \mathrm{Mo} 1.5 \mathrm{Ti}$ maraging steel through high-density and low lattice misfit nanoscale precipitates, Mater. Sci. Eng. A: 715, pp. 174-185. 